\title{
CONSERVATIVE MANAGEMENT OF EXTRA DURAL HEMORRHAGE
}

\author{
By

\section{Amr Ali El-Saghir Zedan, El-Sayed Abd El-Rahman El-Mor and Alaa Rashad Ibrahim Hassan}

Department of Neurosurgery, Faculty of Medicine, Al-Azhar University

Corresponding author: Amr Ali EL Saghir Zedan,

E-mail: amr.elsaghir2014@gmail.com

\begin{abstract}
Background: Extra Dural hematoma (EDH) is a blood clot that develops between the dura mater and the skull, found in $2.5 \%$ to $5 \%$ of head injured patients. Patient with small EDH may be treated conservatively through close observation is advised, yet sudden neurological deterioration may occur.

Objective: To review the literature and to evaluate safety and efficacy of conservative management of extradural hematoma (EDH) in trauma patients with selected criteria.

Patients and methods: This was a hospital based study which was done at the Department of neurosurgery at Al-Azhar University Hospitals and Luxor International Hospital during the period from September 2017 to September 2019. It was conducted on 15 patients with extradural hemorrhage who fulfilling the criteria (volume $<30 \mathrm{ml}$, thickness $<5 \mathrm{~mm}$, midline shift $<5 \mathrm{~mm}$, Glasgow coma scale (GCS) $>8$ ), with exclusion of patients with extradural hematoma who needs surgical evacuation, patients with bleeding tendency and patients with temporal or occipital extradural hematoma. All cases records were reviewed and the pertinent data (clinical history, age, sex, mode of injury) analyzed.

The patients were subjected to conservative treatment through Neurosurgery ICU admission and follow up CT Brain done at 6 hours, 12 hours, 24 hours and 48 hour after admission. Patients were given Analgesics, Antibiotics and Anti epleptics if needed .All patients stayed at ICU for 3 days until they had good conscious level then transferred to Neurosurgery ward for one day then discharged to home. Final CT Brain was done for all patients before discharge to ensure resolution of hemorrhage. Follow up of Patients continued for one month after discharge at clinic.
\end{abstract}

Results: In our study of 15 patients, the conservative management of extradural hematoma continued in all patients $(100 \%)$. This means that conservative management increased, and the mentioned protocol of conservative management gives successful results in the treatment of EDH.

Conclusion: The conservative management gives successful results so we can avoid surgical evacuation in patients with selected criteria.

Keywords: Extradural, Conservative, Hematoma.

\section{INTRODUCTION}

Extra Dural hematoma $(\mathrm{EDH})$ is a blood clot that develops between the dura mater and the skull, it usually has a biconvex shape and it is found in $2.5 \%$ to
$5 \%$ of head injured patients (Tascu et al., 2014).

In $73 \%$ of the EDH the bleeding source is the middle meningeal artery or vein, usually associated to a temporal bone fracture. The blood collection grows 
rapidly in the epidural space, compressing the underlying brain parenchyma. Several observations on EDH have shown that clots confined to the temporal fossa produce uncal herniation more rapidly and with a smaller critical volume than clots located elsewhere (Maugeri et al., 2015).

The classical clinical presentation of EDH includes a brief post traumatic loss of consciousness, followed by a" lucid interval " of variable duration and then headache, depressed conscious state, contralateral hemiparesis and ipsilateral pupillary dilatation. Deterioration usually occurs due to a cerebral herniation (Skadorwa et al., 2013).

In the era before computerized tomography (CT), Extra Dural hematomas were usually diagnosed by invasive and less accurate techniques, such as cerebral angiography, pneumoencephalography, or exploratory burr holes. Determining when surgery is not appropriate is just as critical as establishing when to operate for certain neurologic diseases. The percentage of patients managed non-surgically in clinical series since the 1960s has progressively increased from less than $1 \%$ to more than 60\% (Maugeri et al., 2015).

A patient with small EDH may be treated conservatively through close observation is advised, as delayed, yet sudden neurological deterioration may occur. Though surgical evacuation constitutes the definitive treatment of this condition but many patients can be saved from craniotomy with watchful repeated neurological assessments (Bhau et al., 2012).

This study aimed to determine the appropriate criteria for conservative management of extradural hematoma to avoid unnecessary surgical evacuation.

\section{PATIENTS AND METHODS}

This was a hospital based study which was done at the Department of Neurosurgery at Al-Azhar University Hospitals and Luxor International Hospital during the period from September 2017 to September 2019. It was conducted on 15 patients with extradural hemorrhage who fulfilling the criteria (volume $<30 \mathrm{ml}$, thickness $<5 \mathrm{~mm}$, midline shift $<5 \mathrm{~mm}$, Glasgow coma scale (GCS) >8), with exclusion of patients with extradural hematoma who needed surgical evacuation, patients with bleeding tendency and patients with temporal or occipital extradural hematoma. All cases records were reviewed and the pertinent data (clinical history, age, sex, mode of injury) analyzed.

The patients were subjected to conservative treatment through Neurosurgery ICU admission and follow up CT Brain done at 6 hours, 12 hours, 24 hours and 48 hour after admission. Patients were given Analgesics, Antibiotics and Anti epleptics if needed .All patients stayed at ICU for 3 days until they had good conscious level then transferred to Neurosurgery ward for one day then discharged to home. Final CT Brain was done for all patients before discharge to ensure resolution of hemorrhage. Follow up of Patients continued for one month after discharge at clinic.

\section{Inclusion criteria:}

- Patients with frontal and partial extradural hematoma. 
- Patients with Extradural hematoma volume $<30 \mathrm{~m} 1$, thickness $<5 \mathrm{~mm}$, midline shift $<5 \mathrm{~mm}$, GCS $>9$.

Exclusion criteria:

- Patients with Extradural hematoma volume $>30 \mathrm{ml}$ or thickness $>5 \mathrm{~mm}$ or GCS $<9$ OR midline shift $>5 \mathrm{~mm}$ or presence of focal deficits).

- Patients with bleeding tendency or inappropriate bleeding profile.

- Patients with temporal or occipital Extradural hematoma.

The patients were subjected to ( after primary survey):

- Full detailed history of mechanism of trauma and present illness of patient.

- Full neurological examination of patient including GCS and investigation including (chest $\mathrm{X}$ ray,.....).
- CT Brain was done to each patient after careful neurological examination with careful follow up of the patient and his neurological status.

- Decision for operative intervention for patients depending on conscious level of the patient according to GCS, neurological examination and $\mathrm{CT}$ BRAIN finding including site and size of hemorrhage ( EDH volume $>30 \mathrm{ml}$ or thickness $>5 \mathrm{~mm}$ or GCS $<9$ OR midline shift $>5 \mathrm{~mm}$ or presence of focal deficits).

- Determine if the patient needed ICU or Ward Admission during hospitalization.

\section{Statistical analysis:}

Recorded data were analyzed using the statistical package for the social sciences, version 20.0 (SPSS Inc., Chicago, Illinois, USA). Qualitative data were expressed as frequency and percentage.

\section{CASE PRESENTATION}

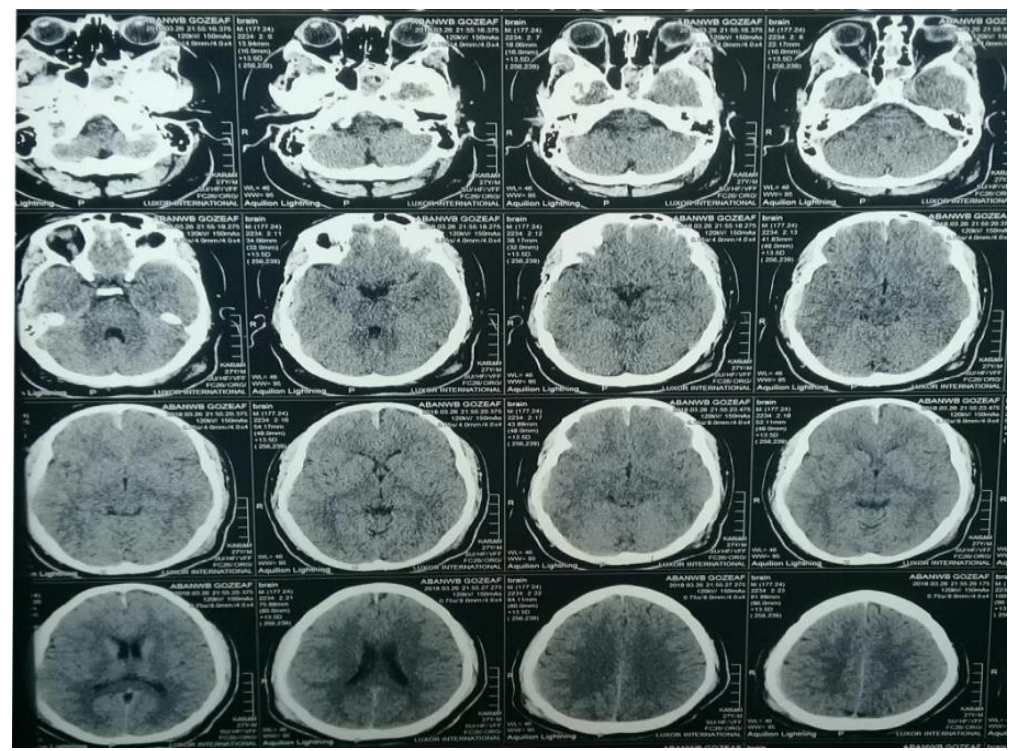

Figure (1): Male patient 27 years old, admitted to ER post Road traffic accident, presented by GCS 13/15, Eye: 3 Verbal:4 Motor:6, full motor power, repeated vomiting, CT brain showed right parietal extradural hematoma. 


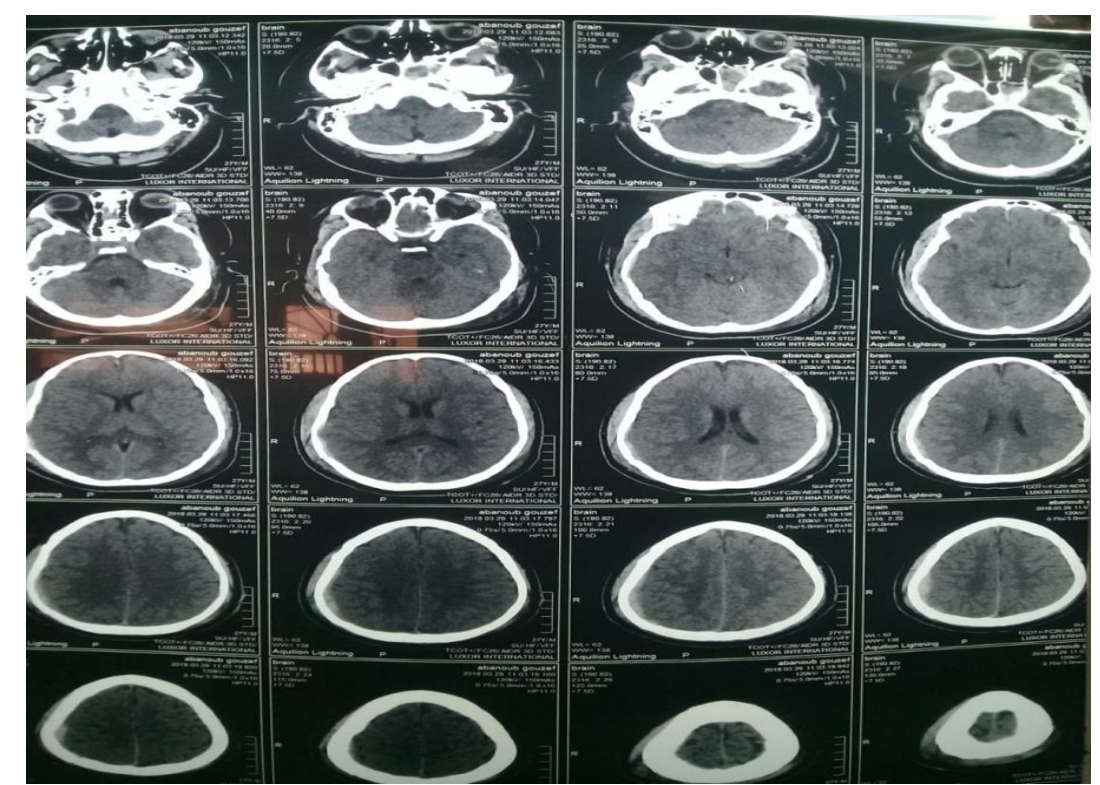

Figure (2): The patient admitted to Intensive care unit under observation and conservative treatment with anti-emetic, antibiotics (Cefotax) and brain stimulant (stimulan) till vomiting improved and stopped, GCS became $15 / 15$ and follow up brain CT showed no increase in the size of extradural hematoma then discharged to neurosurgery ward for one day then discharged to home.

\section{RESULTS}

In our study, the conservative treatment was applied on 15 patients who fulfilled the inclusion criteria (volume $<30 \mathrm{ml}$, thickness $<5 \mathrm{~mm}$, midline shift $<5 \mathrm{~mm}, \mathrm{GCS}>9$ ) and the result was $100 \%$ as no one of them needs surgical intervention. This means that the conservative treatment gives successful results, and can be used in the treatment of small EDH according to the protocol of management.

Age: Most patients between ages 2 to 60 years who are subjected to trauma and were active age of life. The age of the patients was less than 10 years in 1 patient $(6.7 \%), 10-30$ years in 6 patients $(40 \%)$ and more than 30 years in 8 patients (53.3\%) (Figure 3).

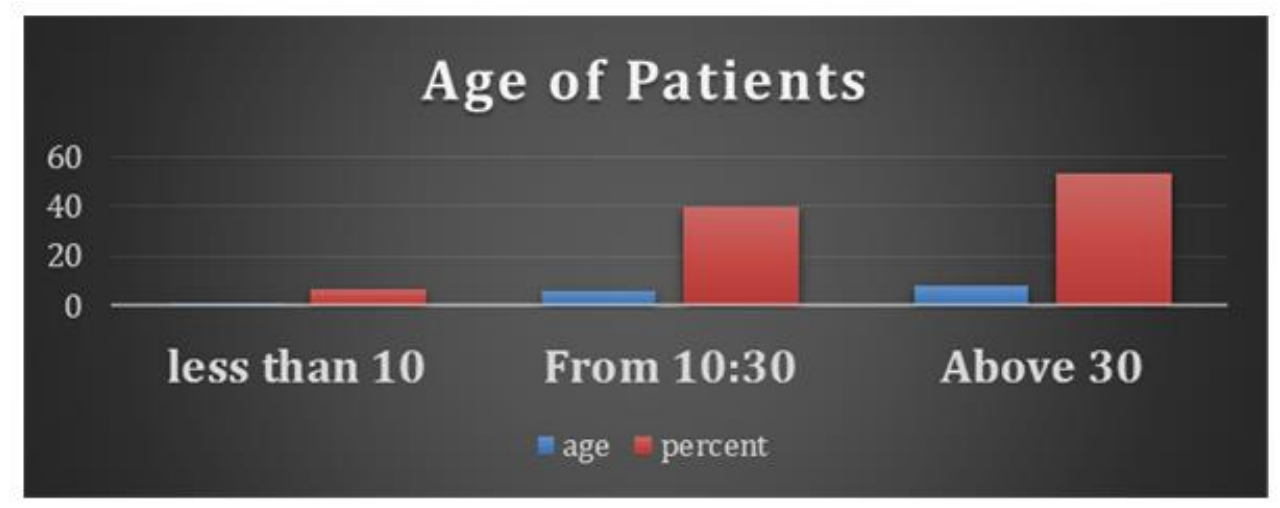

Figure (3): Age of patients. 
Sex: There were 1 female (6.7\%) and 14 males (93.3\%) (Figure 4).

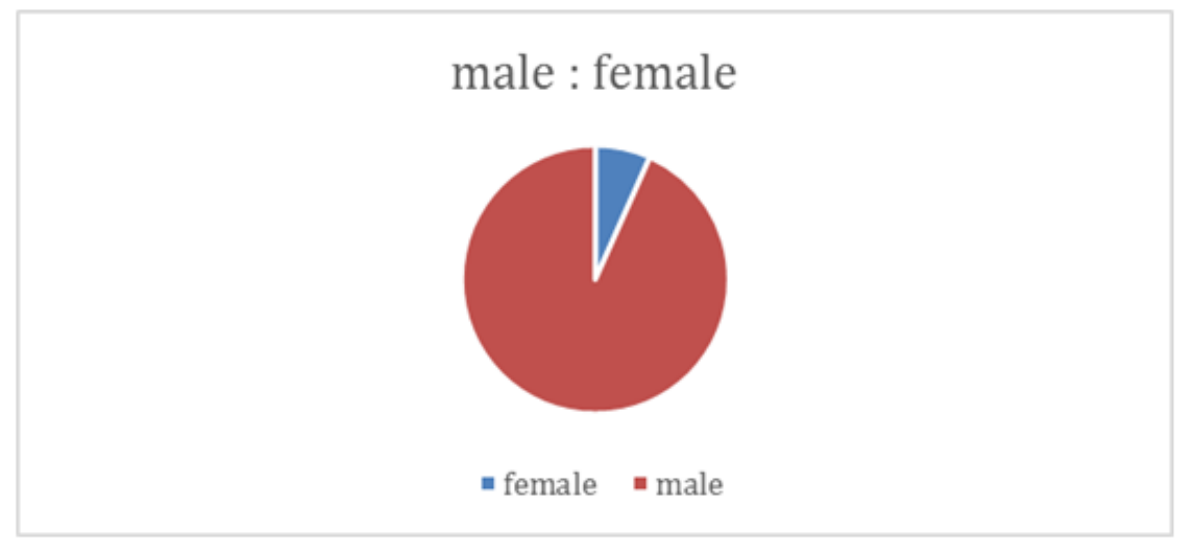

Figure (4): Male to female ratio.

The number of patients with motor car accident was $9(60 \%)$ patients, number of patients with fall from height was 4 (26.6\%) patients and number of patients with heavy object trauma was $2(13.4 \%)$ patients. This means that MCA account for the most frequently mode of trauma (Table 1).

\section{Table (1): Mode of Trauma}

\begin{tabular}{|l|c|c|}
\hline Mode of trauma & No of patients & Percent \\
\hline Motor car accident & 9 & $60 \%$ \\
\hline Fall from height & 4 & $26.6 \%$ \\
\hline Isolated head trauma & 2 & $13.4 \%$ \\
\hline
\end{tabular}

In this study, $66.7 \%$ of patients were fully conscious according to Glasgow coma score $(15 / 15), 20 \%$ of patients were admitted by GCS 14/15, $13.4 \%$ of patients were admitted by GCS 13/15 (Table 2).

Table (2): Glasgow coma scale (GCS)

\begin{tabular}{|c|c|c|}
\hline Number of patients & GCS & Percent \\
\hline 2 & $13 / 15$ & $13.3 \%$ \\
\hline 3 & $14 / 15$ & $20 \%$ \\
\hline 10 & $15 / 15$ & $66.7 \%$ \\
\hline
\end{tabular}

Fracture: 14 patients $(93.3 \%)$ had fissure fracture of their skulls corresponding to the site of $\mathrm{EDH}$, but there is no evidence of fracture in 1 patient $(6.7 \%)$.
The midline shift: 1 patient had midline shift $(3 \mathrm{~mm})$ and 14 patients had no midline shift.

The site: The site of extradural hematoma (Table 3). 
Table (3): The site of EDH

\begin{tabular}{|c|c|c|}
\hline Site of EDH & Number of patients & Percent \\
\hline Parietal & 8 & $53.3 \%$ \\
\hline Frontal & 2 & $13.3 \%$ \\
\hline Temproparietal & 3 & $20 \%$ \\
\hline Frontotemporal & 1 & $6.7 \%$ \\
\hline Occipital & 1 & $6.7 \%$ \\
\hline
\end{tabular}

Results of management: The most common mode of trauma was MCA. Male to female ratio $9: 1$, no patient operated by evacuation. All patients continued on the conservative treatment.

Extradural hemorrhage is most often because of fractured temporal or parietal bone damaging the middle meningeal artery or vein with blood collecting

\section{DISCUSSION}

The classic clinical presentation of an extradural hematoma follows a relatively minor head injury, particularly to temporal region in a young patient with or without brief loss of consciousness, followed by a lucid interval of duration, rapidly followed by headache, depressed conscious state, and contra lateral hemiparesis, ipsilateral dilated pupil. Lucid interval being seen in one-third of patients with extradural hematoma (Chen et al., 2010).

This study was applied on 15 patients came to emergency room with EDH were managed conservatively. The conservative management of extradural hematoma continued in all. This means that conservative management is now increasing according the criteria of the conservative treatment. In general, surgical intervention should be performed when the volume of the lesion exceeds 30 $\mathrm{ml}$ (Marshall et al., 2011).

The site of EDH of 8 patients (53.3\%) was opposite the parietal area, 2 patients between the dura and the skull. It is caused by trauma to the temple just beside the eye, although it may also follow a tear in dural venous sinuses (Malik et al. 2007).

In our study males outnumber female by $9: 1$ as males patients represent 14 while females patients are 1 from 15 patients.

(13.3\%) was opposite the frontal area; 3 patients (20\%) was opposite the tempoparietal area; 1 patient $(6.7 \%)$ was opposite frontotemporal and in 1 patient $(6.7 \%)$ was opposite the occipital region. Miller and Satham (2012) reported that approximately $70 \%$ of extradural hematomas occur in the temproparietal region; while only $10 \%$ are frontal and $10 \%$ are in occipital region, this is against our study as the site was mainly opposite the parietal area and in Miller and Satham was mainly in the temproparietal area (Miller and Satham, 2012).

In the present study patients with GCS $13 / 15$ were 2 cases $(13.4 \%)$ patients with GCS $14 / 15$ were 3 cases $(20 \%)$ and patients with GCS $15 / 15$ were 10 cases (66.7\%), correlated by other studies, e.g. Pang et al. (2010), who were taking only GCS $14 / 15$ or $15 / 15 /$ Tuncer et al. (2010), Dolgun et al. (2011) and Huang et al. (2012) have reported that lower GCS correlated with a more unfavorable outcome, Dubey et al. (2011) reported that (86\%) Patients were GCS 13-15, (7\%) 
GCS 9-12 and (7\%) GCS his study. This also means that GCS affects the results and management of Extradural hematoma.

In our study of 15 patients, the conservative management of extradural hematoma continued in all patients $(100 \%)$. This means that conservative management is now increased and the previously mentioned protocol of conservative management gives successful results in the treatment of EDH.

The most important factor in the follow up is the GCS of the patient which must be more than 9 to follow the conservative management protocol of EDH. Conservative management of EDH has been increased in last years (Hamilton and Wallace, 2010).

\section{CONCLUSION}

It is concluded that EDH caused by many factors, most important cause is trauma that cause bleeding either arterial from middle meningeal artery or venous from dural venous sinuses, or diploic veins, or bone fracture.

The conservative management gives successful results so we can avoid surgical evacuation in patients with selected criteria.

\section{REFERENCES}

1. Bhau K, Bhau S, Dhar $S$ and Kachroo S. (2012): Traumatic extradural hematoma - Role of nonsurgical management and reasons for conversion. Indian Journal of Surgery, 72(2):124-9

2. Chen TY, Wong CW, Chang CN, Lui TN, Cheng WC, Tsai MD and Lin TK. (2010): The expectant treatment of "asymptomatic" supratentorial epidural hematomas. Neurosurgery, 32(2):176-9.

3. Dolgun H, Türkoğlu $E$ and Kertmen H. (2011): Rapid resolution of acute epidural hematoma: case report and review of the literature. Ulus Travma Acil Cerrahi Derg., 17(3):283-85.

4. Dubey A, Pillai SV and Sastry KV. (2011): Does volume of extradural hematoma influence management strategy outcome? Neurology India, 52:443-445.

5. Hamilton $M$ and Wallace C. (2010): Nonoperative management of acute epidural hematoma diagnosed by CT. The neuroradiologist's role. AJNR Am J Neuroradiol., 13:853-859.

6. Huang AP, Huang SJ and Hong WC. (2012): Minimally invasive surgery for acute noncomplicated epidural hematoma: an innovative endoscopic-assisted method. J Trauma Acute Care Surg., 73(3):774-77.

7. Marshall LF, Marshall SB, Klauber MR. and Clark MV. (2011): A new classification of head injury based on computed tomography. J Neurosurg., 75:S14-S20.

8. Maugeri R, Anderson DG, Graziano F, Meccio F, Visocchi $M$ and Iacopino DG. (2015): Conservative vs. Surgical Management of PostTraumatic Epidural Hematoma: A Case and Review of Literature. Am J Case Rep., 16:811-817.

9. Miller JD and Statham PF. (2012): Surgical management of traumatic intracranial hematomas. In: Schmidek $\mathrm{HH}$, Sweet WH, eds. Operative 
neurosurgical techniques, 3rd edn., Philadelphia: WB Saunders Company, Pp. 73-80.

10. Pang D, Horton JA and Herron JM. (2010): Nonsurgical management of extradural hematomas in children. J Neurosurg, 59(6):958-71.

11. Skadorwa T, Zygańska E, Eibl M and Ciszek B. (2013): Distinct strategies in the treatment of epidural hematoma in children: clinical considerations. Pediatr Neurosurg., 49(3):166-71.
12. Tascu A, Pascal C, Iencean SM and Gorgan MR (2014): Aggressive or conservative management in extradural hematomas in children: A challenging neurosurgical choice. Roneuro, 21: 384-393.

13. Tuncer R, Kazan $S$ and Uçar $T$. (2010): Conservative management of epidural haematomas: prospective study of 15 cases. Acta Neurochir (Wien)., 121:48-52. 


\section{العلاج التحفظى للنزيف خار ج الأم الجافية}

عمرو على الصغير زيدان فرجانى، السيا عبد الرحمن المر، علاء رشاد ابراهيم

\section{قسم جراحة المخ والأعصاب، كلية طب، جامعة الأزهر}

\section{E-mail: amr.elsaghir2014@gmail.com}

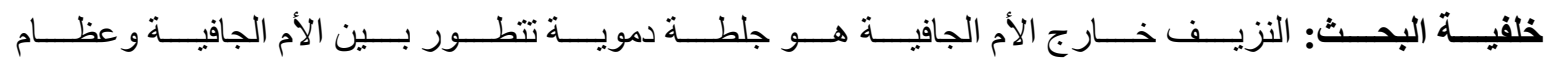

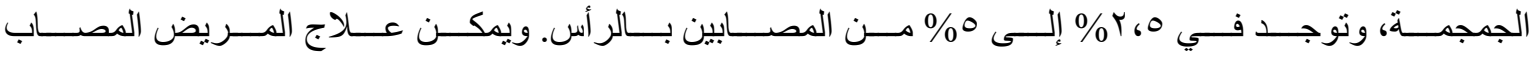

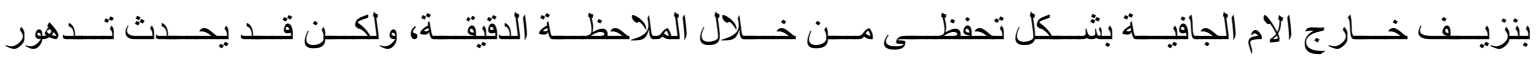
عصبي مفاجئ.

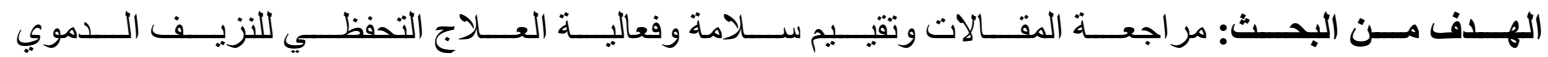
خارج الام الجافية في مرضى الحو ادث بمعايير مختارة.

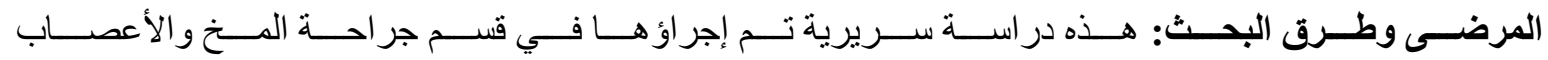

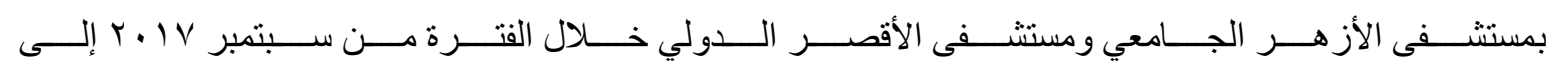

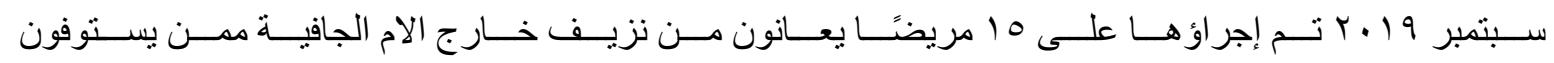

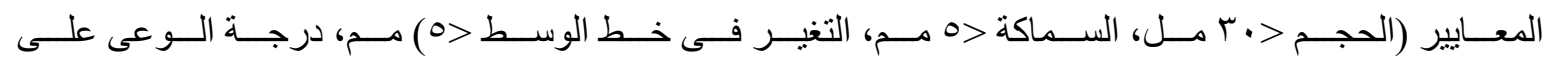

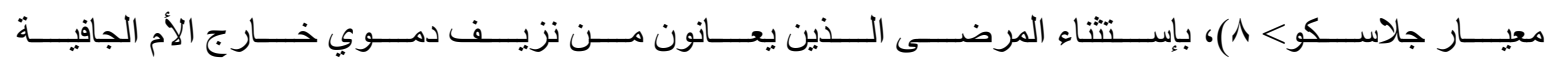

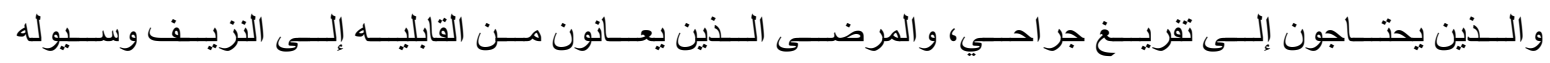

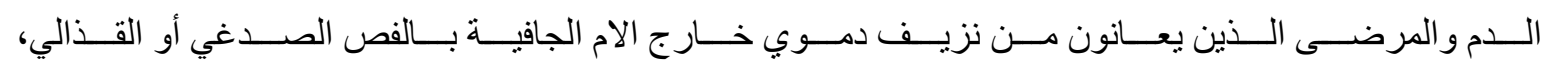

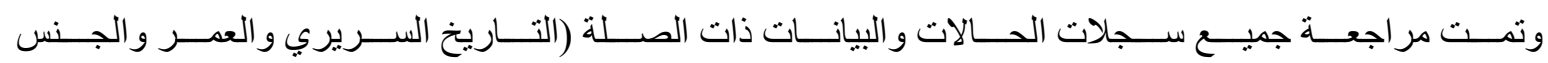
والوضع من الاصابة) تحليلها.

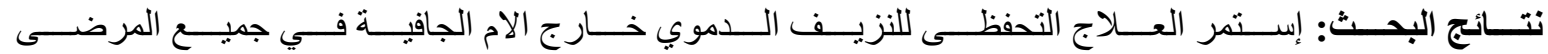

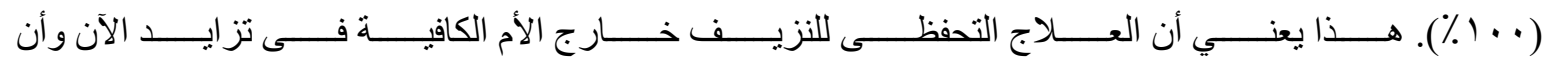
البروتوكول المذكور للعلاج التحفظى يعطي نتائج ناجحة في علاج النزيف خارج الأم الجافية.

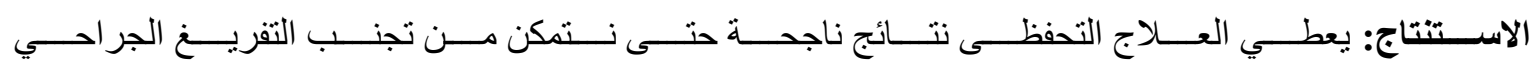
للمرضى ذوي المعايير المختارة. الكلمات الدالة: ار ج الجافية، محافظ، ورم دموي. 